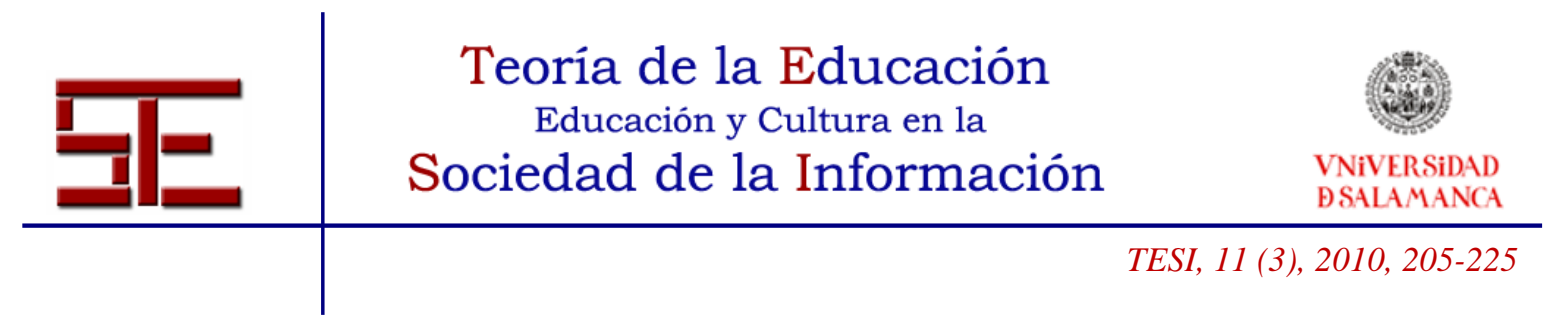

\title{
EL PERFIL DEL EDITOR DE JUEGOS DE ROL
}

Resumen: El presente trabajo estudia y analiza, a través de diversas encuestas personalizadas, el perfil tipo que presentan los profesionales que se dedican al arte de editar libros de rol en España.

Palabras clave: España; industria editorial; juegos de rol; perfil del editor.

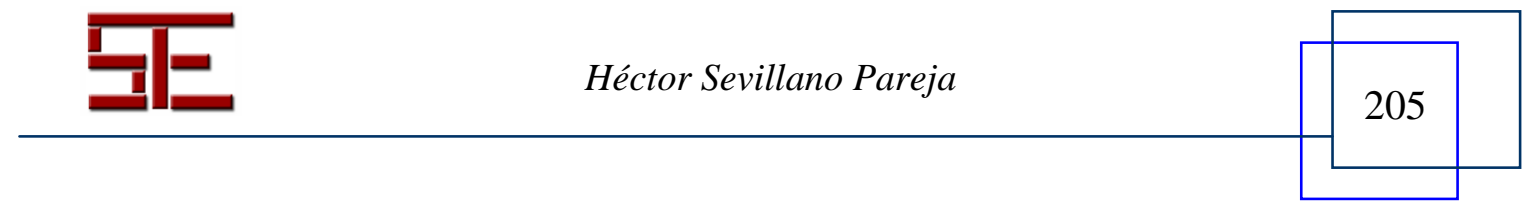




\section{THE PROFILE OF ROLEPLAYING GAMES EDITOR}

Abstract: This work study and analyze, across diverse personalized surveys, the profile of publisher, this kinds of professionals who devote themselves to the art of editing roleplaying games books in Spain.

Key words: Spain; publishing industry; roleplaying games; profile of editor. 


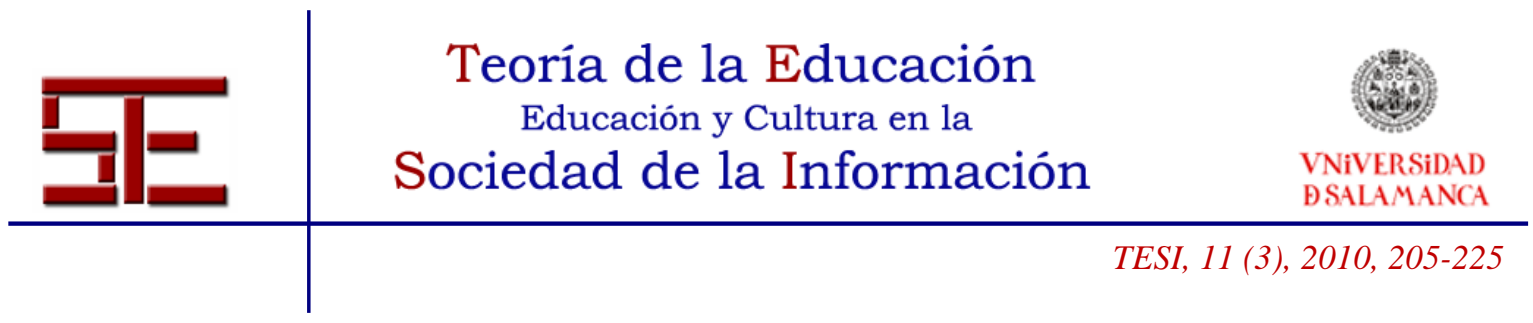

\section{EL PERFIL DEL EDITOR DE JUEGOS DE ROL}

Fecha de recepción: 15/07/2010; fecha de aceptación: 08/09/2010; fecha de publicación: 30/11/2010

Héctor Sevillano Pareja

hsevillanopareja@gmail.com

Universidad de Salamanca

\section{INTRODUCCIÓN}

En este trabajo han colaborado tres editoriales ${ }^{[1]}$ aportando otros tantos editores ${ }^{[2]}$. Las editoriales representadas son: Devir Iberia; Nosolorol y Ediciones Sombra. Obviamente

${ }^{[1]}$ Si se quiere conocer algo de la historia editorial de los juegos de rol en España, conviene leer el artículo que a continuación reseñamos. En él hay una entrevista a Francesc Matas, presidente de Joc Internacional. Editorial pionera de los juegos de rol en nuestro país, con juegos míticos como la mencionada La Llamada de Cthulhu, RuneQuest o El Señor de los Anillos, entre otros. Aunque esta empresa nació en 1984 y durante bastantes años fue una de las empresas punteras de esta industria sin embargo diversos problemas la llevaron a no ver la luz del nuevo milenio. Algunos profesionales del sector atribuyen su cierre a un exceso de líneas de juego poco rentables, otros lo atribuyen a que la editorial no se hiciera con los derechos para la traducción de AD\&D y posteriormente D\&D. La referencia es esta: REVISTA LÍDER (1995). Entrevista a Francesc Matas, 10 años de Joc Internacional. Líder, 45, 14-15.

${ }^{[2]}$ De la figura del editor hay múltiples definiciones que describen las funciones que debe poseer todo buen editor. Nosotros hemos escogido tres puntos de vista para que nos sirvan de punto de partida:

- Según Pierre Bourdieu (Bourdieu, 1999, 3): “...L'editeur est celui qui a le pouvoir tout à fait extraordinaire d'assurer la publication, c'est-à-dire de faire accéder un texte et un auteur à l'existence publique, conque et reconnue. Cette sorte de "création" implique le plus souvent une consécration, un transfert de capital symbolique (analogue à celui qu'opère une préface) qui est d'autant plus important que celui qui l'accomplit est lui-même plus consacré, à travers

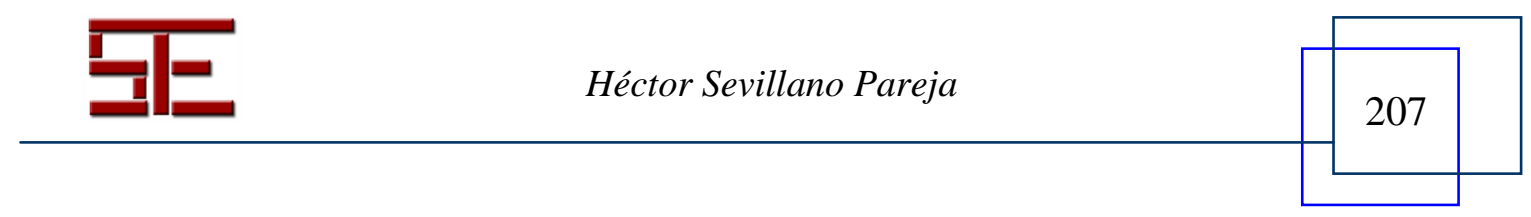




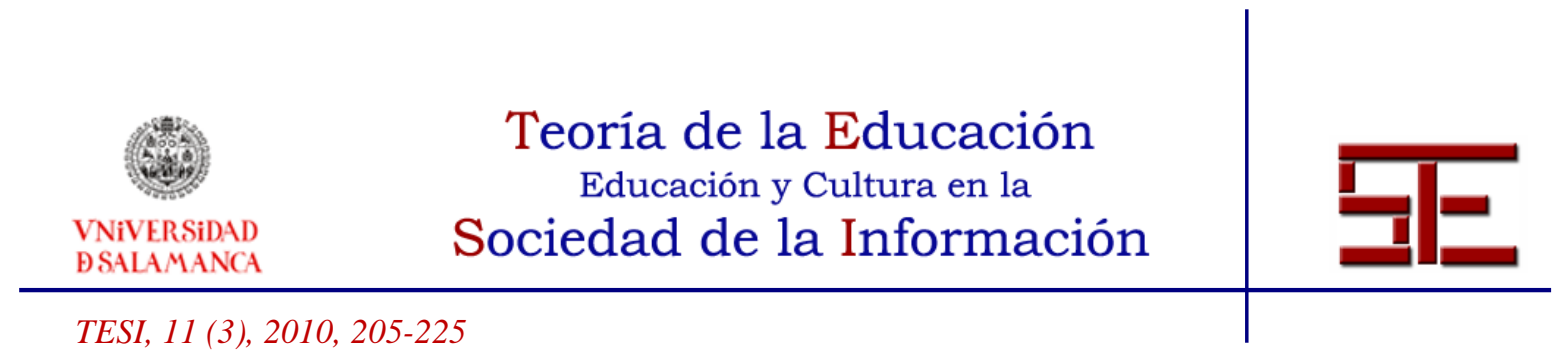

hubiéramos preferido que hubieran participado más editoriales, especialmente La Factoría de Ideas $^{[3]}$ y Edge Entertainment (ya que con ellas y las anteriormente mencionadas se cubriría casi todo el mercado de lo editado actualmente en España), pero no ha sido posible. La primera porque no ha participado en ningún momento en la investigación, pese a los múltiples intentos llevados a cabo para obtener su colaboración; la segunda, que pese a que en un primer momento sí que mostró disposición a aportar datos para la investigación, finalmente se cerró en banda. Si bien contar con tres de las cinco mayores editoriales del sector no es nada despreciable. Son empresas relativamente jóvenes en el ramo de la edición, cuentan con personal variado,

notamment son "catalogue", ensamble des auteurs, eux-mêmes plus ou moins consacrés, qu'il a publiés dans le passé...”.

- Para el director general de la División editorial Librerías del Grupo Planeta, Jesús Badenes (Peces, 2006, 46), el editor debe percibir tres necesidades de los lectores:

1. Información

2. Formación

3. Generar un estado de opinión, y eso igual que un periódico lo hace a través de su línea editorial, un editor lo hace a través de la opción que toma para su catálogo...”.

- En palabras de Nancy Sánchez y Yuniar Díaz (Sánchez Tarragó y Díaz Álvarez, 2005, 10-11), hay cinco tareas que el editor debe controlar:

1. “...Selección (de contenidos, de autores, de árbitros, etc.)

2. Finanzas

3. Organización

4. Agregación (agregar valor)

5. Marketing

...Esta última tarea integra una de las tendencias fundamentales relacionadas con las competencias profesionales: la orientación al mercado...”.

${ }^{[3]}$ Para conocer algo de la línea editorial de esta compañía se pueden leer las palabras de su director, París Álvarez en declaraciones a la revista Delibros: Álvarez, P. (2006): Panorama 2005 edición ficción, La Factoría de Ideas. Delibros, 19 (194), 56.

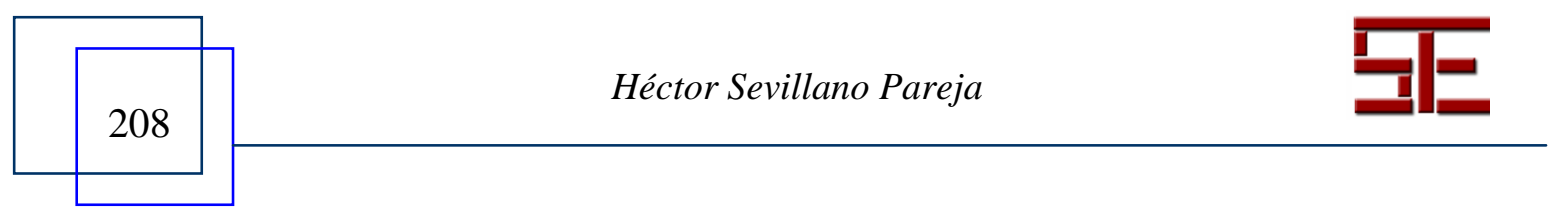




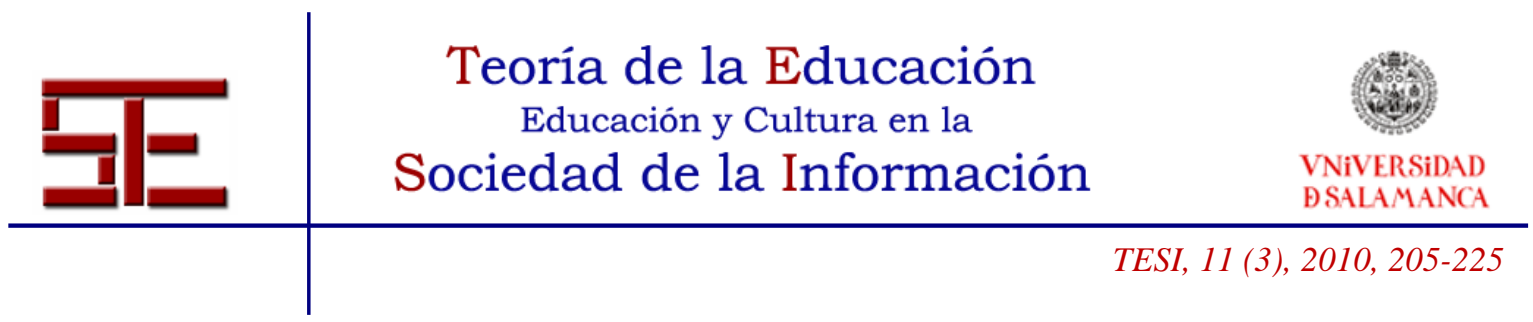

que recorre todo el campo de los juegos de rol lo que nos proporciona información suficiente como para poder hacer un perfil definido del editor. Los encuestados han sido los que figuran a continuación:

Xavi Garriga $^{[4]}$ : Editor de Devir Iberia ${ }^{[5]}$, anteriormente trabajó en Farsa's Wagon ${ }^{[6]}$. Es uno de los principales artífices de la difusión y del éxito de la tercera edición de $\mathrm{D} \& \mathrm{D}^{[7]}$

[4] Hay una entrevista bastante curiosa realizada a este editor, aunque particularmente centrada en los juegos de tablero en: VASEL, T.: Real men play board games, Interviews by an Optimist 44 - Xavier Garriga. The Dice Tower. 9 de junio de 2005. [En línea].

< http://www.thedicetower.com/interviews/int044.htm >. [Consulta: 1 de abril de 2009].

${ }^{[5]}$ Devir es una editorial de origen brasileño fundada en 1987 en São Paulo. La filial española se creó en diciembre de 2000 y está ubicada en Barcelona. Además del material antes mencionado, Devir ha publicado libros de rol de: Hackmáster, Midnight, Juego de Tronos y diverso material de D20 no relacionado con D\&D (directamente, aunque precisan de los básicos de dicho juego para poder utilizarse). Más información en: http://www.devir.es/index.php.

${ }^{[6]}$ A cerca de sus inicios en esta editorial se pueden leer los comentarios de Garriga durante la celebración de las Gen Con de 1994 en Barcelona. La referencia es la siguiente: SÁNCHEZ, I.; POUJADE, J. C. (1995): GENCON 94, el principio de algo grande. Dosdediez, 7, 18-23. Además de éste artículo hay otra entrevista de su etapa en Farsa's Wagon: García Castro, E. (2000): El carro de la Farsa, entrevista a Xavi Garriga. Líder, 5, 30-35. Apenas un año después, en 2001, dejaba esta editorial y se unía a Devir Iberia. Este cambio de editorial hay que enmarcarlo en el contexto de transición en el que se encontraba la industria de los juegos de rol. En el año 2000 desaparecía AD\&D y daba paso a la tercera edición de D\&D. Entre tanto y en los últimos años TSR había sido adquirida por Wizards of the Coast y ésta a su vez había sido comprada por Hasbro. En España este movimiento editorial derivó en que Martínez Roca en el año 2000 perdiera la licencia, con la cancelación de AD\&D, en favor de Devir Iberia, que ya había llegado a diversos acuerdos con Wizards en Brasil y que poseía la licencia para España de la tercera edición de D\&D. En este contexto es donde Xavi Garriga tiene cabida. Hasta el año 2000 era el coordinando / gestor de la producción de la línea de AD\&D para Martínez Roca, de manera que cuando Devir se hizo con los derechos de D\&D, él paso desde Farsa's Wagon a Devir parecía lógico.

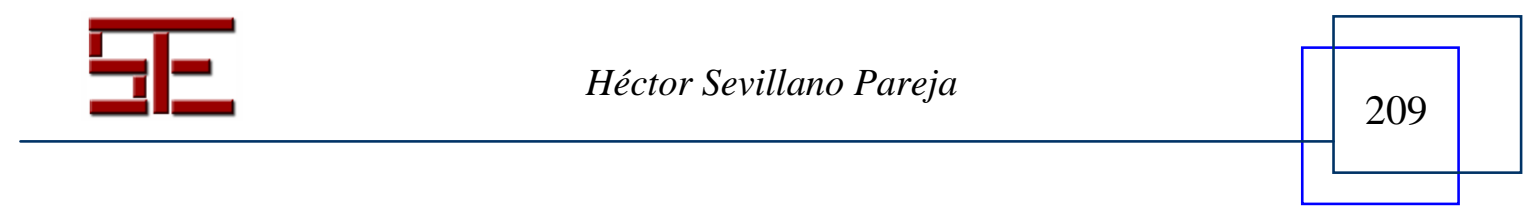




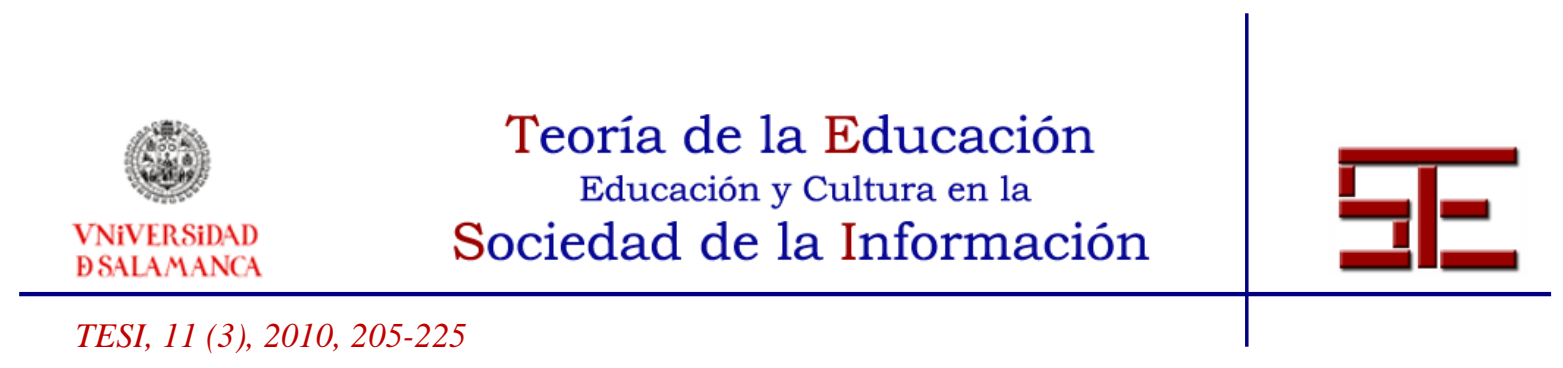

en España y responsable de la nueva edición de este juego, es decir, su cuarta edición. Al margen de D\&D, ha dirigido otras líneas de la editorial como Star Wars o El Capitán Alatriste. En la actualidad todas las líneas de rol de la editorial llevan varios años paralizadas, salvo el mencionado D\&D. Mientras tanto han centrado su línea editorial en los juegos de tablero y en las cartas de Magic.

Juan Carlos Herreros Lucas $^{[8]}$ : Es autor y editor de Ediciones Sombra ${ }^{[9]}$, aunque también trabajó en Cronópolis. Destacan en esta editorial las obras creadas por él, como: Comandos de Guerra, Exo y Rol Negro ${ }^{[10]}$, además de su revista Sire y su revista on line Desde el Sótano.

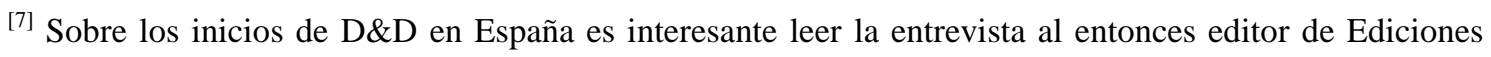
Zinco, Luis Vigil, allá por el año 1994: DÍAZ, O.; POUJADE, J. C. (1994): La irresistible ascensión. Dosdediez, 5, 53-58.

${ }^{[8]}$ Por distintos problemas de distribución nos ha sido imposible consultar directamente material de esta editorial. Para suplir esta carencia se ha recurrido a la consulta de diverso material disponible en Internet.

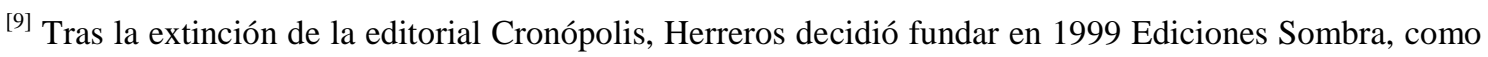
modo de dar salida al material que tenía en mente y que hasta ese momento no había encontrado su hueco en las editoriales de entonces. Se puede encontrar más información sobre los productos de la editorial en: http://www.edsombra.com/dbsombra/index.asp?apa=14

[10] Para conocer algo más acerca de este editor conviene revisar el siguiente enlace: EQUIPO NOSOLOROL: Entrevista a Juan Carlos Herreros (Autor de Rol Negro). Nosolorol revista on line. 17 de mayo de 2006. [En línea]. < http://www.nosolorol.com/revista/index.php?nrev=36\&nsec=13 > [Consulta: 1 de abril de 2009].

Sobre este punto, también tiene su importancia el artículo que exponemos a continuación: NOREN: Entrevista a Ediciones Sombra. Comicvia. 19 de noviembre de 2007. [En línea].

< http://www.comicvia.net/blog/?p=2232 y http://www.comicvia.net/blog/?p=2233 >. [Consulta: 20 de febrero de 2008].

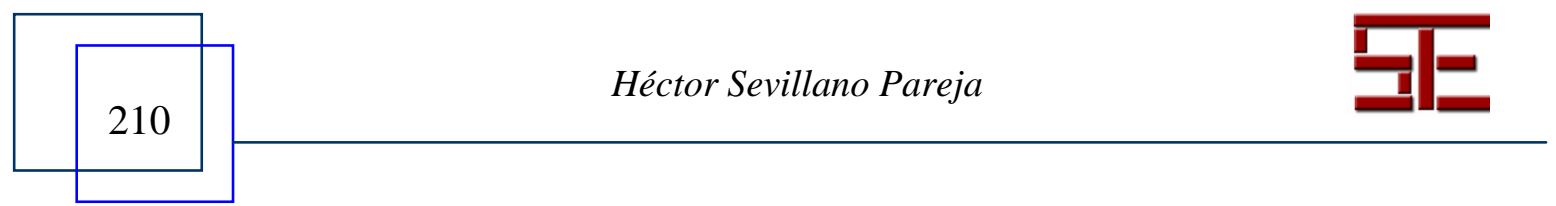




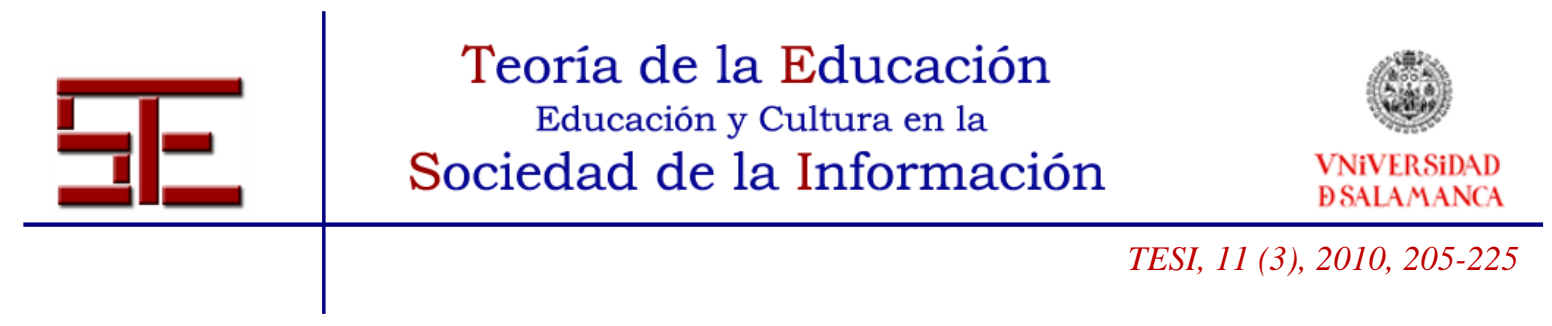

Manuel José Sueiro y Abad: Además de editor, es autor. Para Nosolorol ${ }^{[11]}$, su editorial, ha publicado: sLAng ${ }^{[12]}$, Lances; e Inocentes. Aparte de sus libros, en el catálogo de Nosolorol se pueden encontrar los siguientes títulos: Usagi $\quad$ Yojimbo $^{[13]}$, diverso

[11] Tras el fracaso de la editorial Libros Ucronía, varios de sus componentes se animaron a hacer una revista on line denominada Nosolorol (http://www.nosolorol.com/), cuyo nombre deriva de que los contenidos la misma no iban a centrarse únicamente en él. Tras el éxito de visitantes que tuvo, se decidieron a constituirse como editorial para intentar publicar material fundamentalmente español. Dieron este paso en 2006, fijando su residencia en Madrid y hasta el momento han estado participando en diferentes jornadas de aficionados con bastante aceptación. A este éxito ha colaborado, a parte de la revista, la tienda on line de la editorial (cuya ubicación física estaba hasta hace poco en Córdoba y que ahora han reubicado en Madrid) y en donde además de material de la propia editorial, también han estado sirviendo hasta hace poco material de otras compañías, de importación y libros descatalogados.

${ }^{[12]}$ Como en el caso de Juan Carlos Herreros, en éste artículo hay pormenores editoriales que resultan interesantes y por ello exponemos la referencia: EQUIPO NOSOLOROL: Entrevista a Manu y Ángel (Coautores sLAng). Nosolorol revista on line. 13 de marzo de 2006. [En línea]. < http://www.nosolorol.com/revista/index.php?nrev=34\&nsec=11 > [Consulta: 1 de abril de 2009]. Igualmente, consideramos útil consultar estos otros dos artículos on line:

- DEUS101: Entrevista a los muchachos de Nosolorol. Dragonmania. 18 de febrero de 2007. [En línea]. < http://www.ociojoven.com/article/articleprint/976605/ > [Consulta: 1 de abril de 2009].

- NOREN: Entrevistamos a Manuel J. Sueiro, de Nosolorol Ediciones. Comicvia. 8 de febrero de 2007. [En línea]. < http://www.comicvia.net/blog/?p=1196 >. [Consulta: 20 de febrero de 2008].

${ }^{[13]}$ HOLMGREN, J.; HIEL, P. (2006): Usagi Yojimbo. Madrid, Nosolorol.

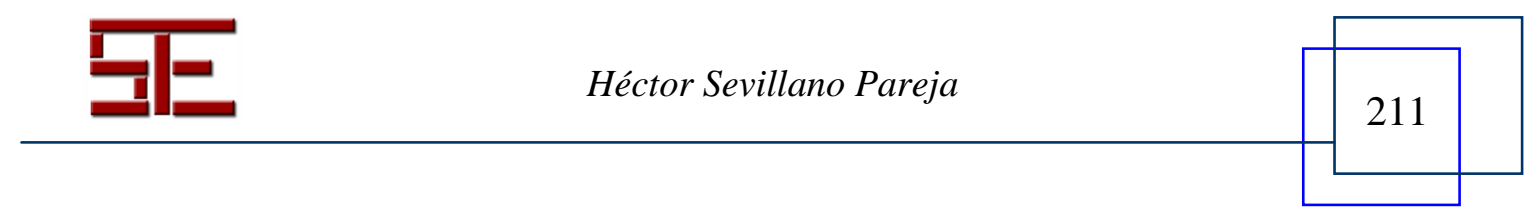




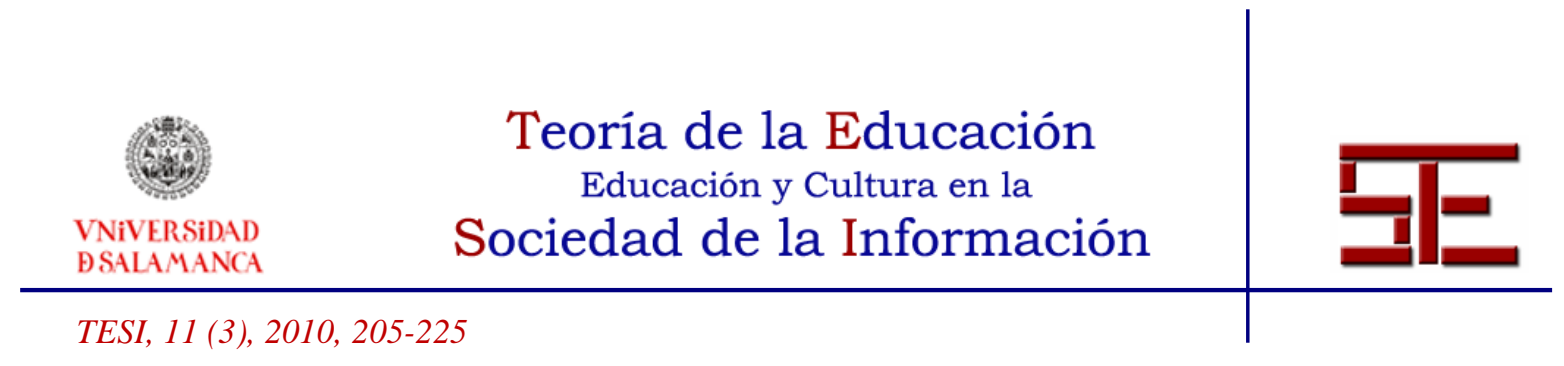

material para D20 ${ }^{[14]}$, Roleage $e^{[15]}$ y Mutants \& Masterminds, además de libros de ayuda para el juego, librojuegos, etc.

\section{2.- RESULTADOS DE LA INVESTIGACIÓN}

Después de esta introducción pasamos a la información de los cuestionarios. En primer lugar, dichos cuestionarios han sido elaborados con preguntas similares, salvo en las ocasiones en que ha sido necesario adaptarlos a los planteamientos específicos de cada editorial. Los resultados son éstos:

Todos los editores con los que se pudo contactar son hombres.

En cuanto a las preguntas del cuestionario, quisimos saber cómo enfoca un editor el mercado de los juegos de rol. O dicho de otro modo, ¿consideran los editores que el sector está en crisis? Al respecto opinan que hay un cierto estancamiento y que el mercado necesita un revulsivo, que quizá venga de la mano de la $4^{\text {a }}$ edición de $D \& D$. Esto parece confirmar la respuesta sobre la prioridad editorial en los productos que publican, todas editan rol, pero también trabajan con otros productos para diversificar la oferta y adquirir nuevos clientes. Para poder conocer de primera mano cómo deben orientar su producción, utilizan los foros de aficionados que han creado en sus propias páginas webs.

${ }^{[14]}$ Como el libro creado por Sacaluga, 99 espadas, cuya referencia es: DÍAZ SACALUGA, I. (2006): 99 espadas. Madrid, Nosolorol.

${ }^{[15]}$ Uno de sus últimos proyectos editoriales y que está llamado por sus características a ser uno de los juegos estrella de la editorial. Pese a que en diversas ocasiones Sueiro se había posicionado en contra de editar juegos medievales-fantásticos (incluso en el foro de la propia editorial), al final la calidad del producto le ha hecho variar de criterio. La referencia es: GONZÁLEZ GUTIÉRREZ, P.; MAÑAS CARBONERO, L.; LANZA CEBRIÁN, J. D. (2007): Roleage, evolved roleplaying game. Madrid, Nosolorol.

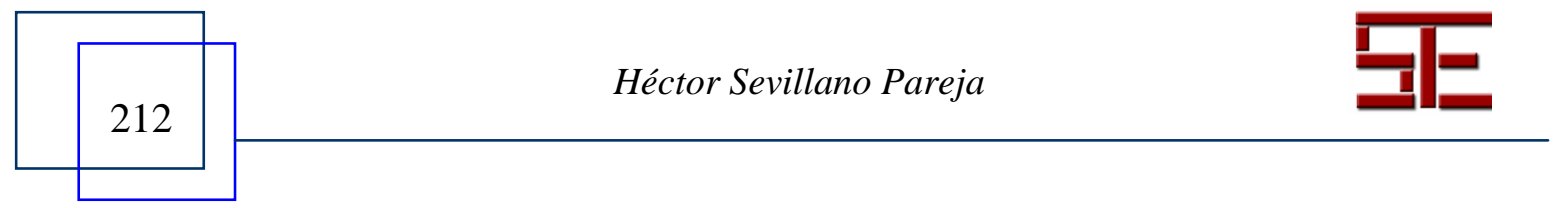




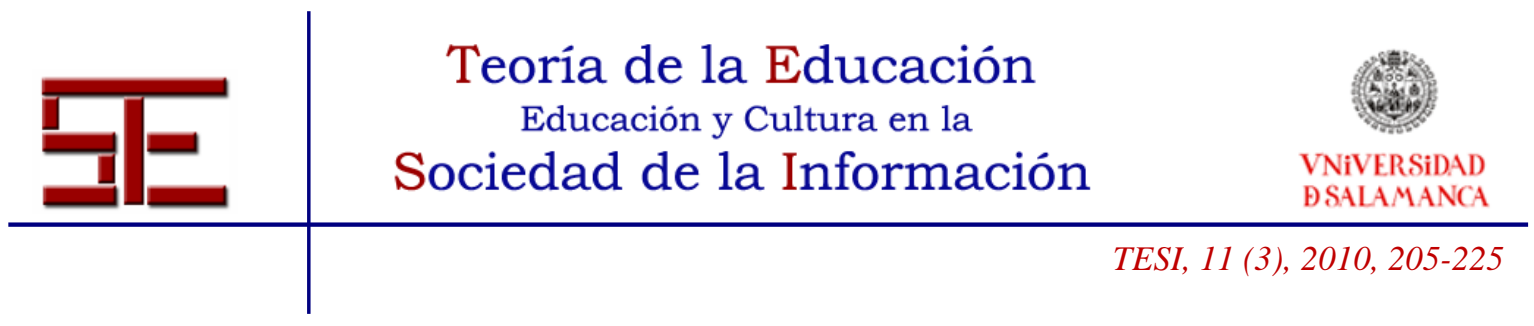

Los editores han constatado que el uso de las nuevas tecnologías, además de permitirles conocer de primera mano qué productos demandan sus posibles clientes, les permite acceder a un mercado hasta ahora poco explotado, como es el mercado de los núcleos rurales. La ampliación de la población que tendrá acceso a Internet localizada en los núcleos rurales, que hasta hoy recibían poca información de sus productos (al haber poco mercado potencial no se creaban tiendas especializadas de rol que se mantuvieran con esa demanda y por lo tanto ni se servían revistas ni libros de rol), permitirá un aumento del mercado. Al detectar las editoriales la pérdida de clientes potenciales, todas ellas han abierto tiendas virtuales que sirven a dichos núcleos.

Sobre el sistema D20 consideran que es mayoritario pero no domina el mercado, eso es exclusivo de los Estados Unidos.

En lo tocante a la piratería, los tres editores consideran que sus productos no han sido muy copiados. Uno de ellos cree que si hubiese sido al contrario, es decir, que sus productos hubieran sido muy pirateados habría tenido que cerrar; otro opina que la copia puede haber servido de paso previo a comprarse el producto, pero que esta idea todavía era objeto de discusión en la editorial; y el tercero que lo que más daño les ha hecho es la copia informática, pero que tampoco les quedaba claro en la empresa cuánto se había perdido por ello.

En lo relativo al proceso de selección de manuscritos también hay diversidad. Dos de las empresas se decantan por buscar gente que escriba lo que la empresa quiere sacar y en el caso de las traducciones, seleccionando lo que se va a publicar (normalmente guiados por criterios económicos). En cuanto a la tercera editorial, el proceso se inicia por la selección de las obras terminadas que llegan a la editorial. Ésta se hace entre los editores-jefe y un consejo de consultores expertos (a partir de unos criterios de calidad, originalidad, interés comercial y coherencia con la línea editorial). En las otras dos editoriales la responsabilidad final la acarrea el editor. En resumen los criterios para seleccionar una obra serían un cóctel entre originalidad, calidad, criterios económicos e intuición del editor.

reguntados por si efectuaban análisis del mercado, respondieron que no. En el mejor de los casos consiste en hablar con las tiendas, ir a jornadas, hablar con los clientes, realizar encuestas vía web, etc. Todo con tal de conectar con el lector y acertar en el próximo lanzamiento. De momento y en opinión de los tres editores, estamos probablemente en una etapa de transición, si no estancados. El mayor problema es que

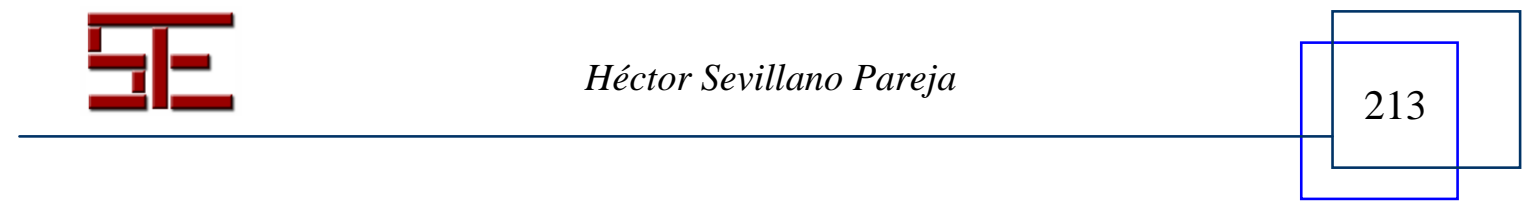




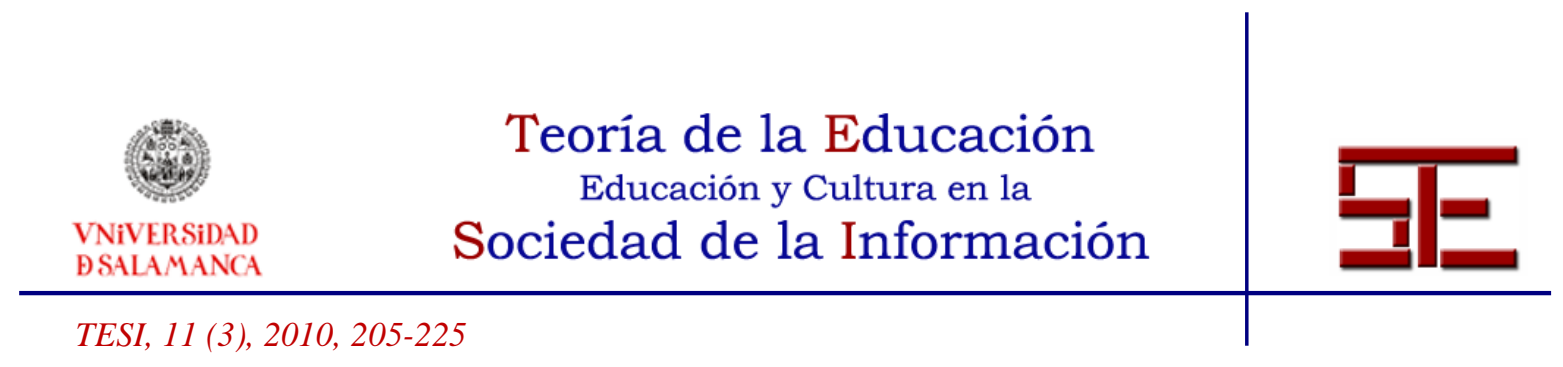

el mercado es reducido y que incluso llegando a grandes cantidades de aficionados, el mercado seguiría siendo pequeño, con lo que para satisfacer al cliente desde la perspectiva editorial tendrían que arriesgar y, en ocasiones, mucho. Esto se ve contrastado con la disminución del número de editoriales en activo desde los años 90 hasta la actualidad. De facto, hasta ahora las editoriales han apostado por publicar títulos consagrados en otros países, en lugar de arriesgar y sacar al mercado títulos de autores españoles. Esto queda demostrado por la masiva presencia en el mercado de traducciones de juegos extranjeros, hecho comprobado en la base de datos del ISBN.

Encuestados sobre el número de títulos (sin importar el género) que llevan editados, las editoriales se mueven entre los veintinueve de Nosolorol, los veintisiete de Sombra o los más de doscientos de Devir. De ellos de rol serían, siguiendo el mismo orden y respectivamente, diecinueve, once y algo más de un centenar. Divididos todos los títulos, la producción anual de cada una de las editoriales sería, individualmente, de nueve para Nosolorol, tres o cuatro para Sombra y cincuenta para Devir (veinte de ellos de rol). Eso sí, salvo dos títulos de Devir, el resto del catálogo de las tres editoriales está en activo.

La tirada media, como no podía ser de otro modo, depende de la capacidad que tenga la editorial. Devir, que es la mayor de las empresas entrevistadas, hace tiradas de 1.500 ejemplares en el caso de obras muy especializadas (por debajo de estas cifras no cubren costes) a 4.000 (normalmente los básicos). Estas cifras andan muy lejos de las posibilidades de las otras editoriales. Sombra, en el caso de los básicos, hace tiradas de 500 a 1.000 ejemplares, y para los módulos aproximadamente de 250 a 500 . Cifras muy cercanas a las de Nosolorol que de media se ubican en torno a 300 ó 500 ejemplares $^{[16]}$. Todo este proceso logra sacar al mercado más títulos, fidelizando al cliente, y ello debido a la bajada de costes de producción, lo que permite tiradas pequeñas para un mercado como el del rol, pequeño.

${ }^{[16]}$ Como bien indica Ana Velasco (Velasco Suárez, 2000, 8), “... las nuevas tecnologías [de la impresión digital] hacen posible la realización de escasísimas tiradas y éstas pueden ser rentables llegando a pequeños sectores de lectores...”.

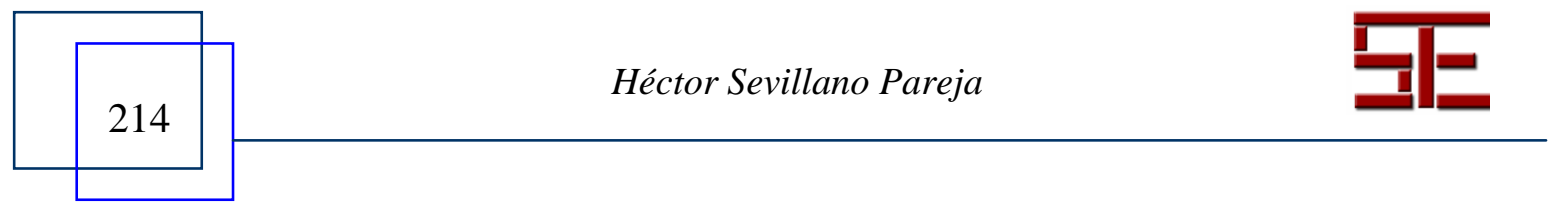




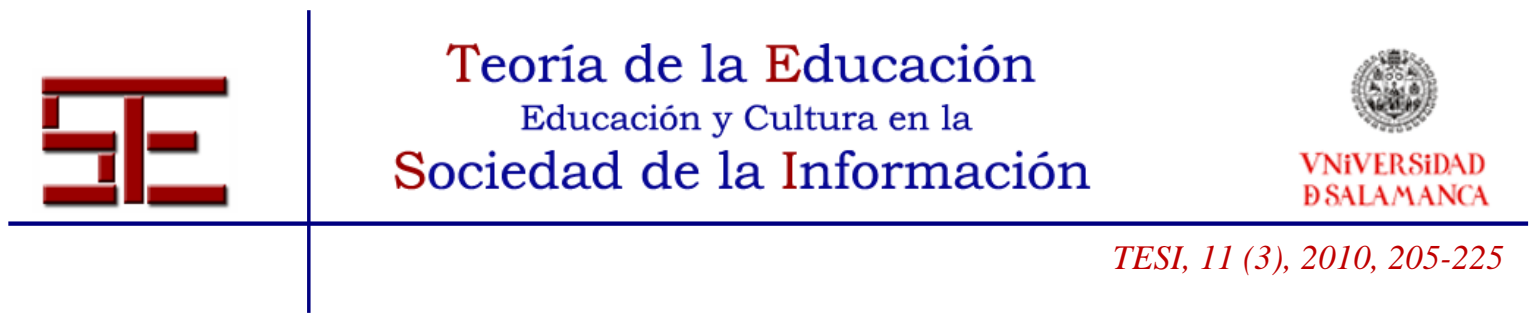

Las reediciones y las reimpresiones están relacionadas con la tirada media. Todas ellas han hecho reimpresiones (en el caso de las editoriales pequeñas de apenas 100 ejemplares, en el caso de Devir más grandes pues cada año reimprimen los manuales básicos de $D \& D)$. Sin embargo, reediciones todavía no ha hecho ninguna.

En lo relativo a las autoediciones, solamente Sombra las ha hecho ${ }^{[17]}$. Lo que comparten al cien por cien es que ninguna ha realizado coediciones o coproducciones.

Al preguntarles sobre las traducciones que editan al año, vuelve a haber respuestas variadas. Sombra no hace traducciones, Nosolorol ha hecho tres y Devir justo al contrario, casi todo lo que publica son traducciones.

También nos interesó saber qué facturación podía llegar a alcanzar una empresa de estas características. Presuponíamos que con las cifras de negocio que se manejan iba a haber diferencias y claramente las hubo. Los márgenes están marcados por el mínimo de Sombra, 40.000€ y el máximo de Devir, 700.000€. Nosolorol no aportó datos al respecto. Se trató además el tema de las subvenciones y ninguna de las editoriales recibe subvenciones públicas.

En el estatus jurídico de las empresas también existe una separación clara, Devir es una sociedad limitada y en las otras dos, sus editores están dados de alta como autónomos. Esta pregunta, la del estatus jurídico, va unida al número de personas que componen la empresa. Todas las editoriales se definen como pequeñas, pero como vamos viendo hay distintos grados. Devir emplea a dieciséis personas, Sombra y Nosolorol a dos (incluyendo en este recuento al editor). Lo que todas reconocen es que además de esta plantilla fija cuentan con colaboradores más o menos fijos y freelance para momentos puntuales.

Dado que todas las editoriales se definían como pequeñas, y visto el panorama de absorciones empresariales en Estados Unidos, quisimos saber si tenían miedo de ser compradas por una empresa mayor. La respuesta fue similar en todas ellas, consideran

${ }^{[17]}$ Para este punto no se ha tenido en cuenta que el autor publique en su editorial, sino solamente el material proveniente de peticiones de fuera de la editorial.

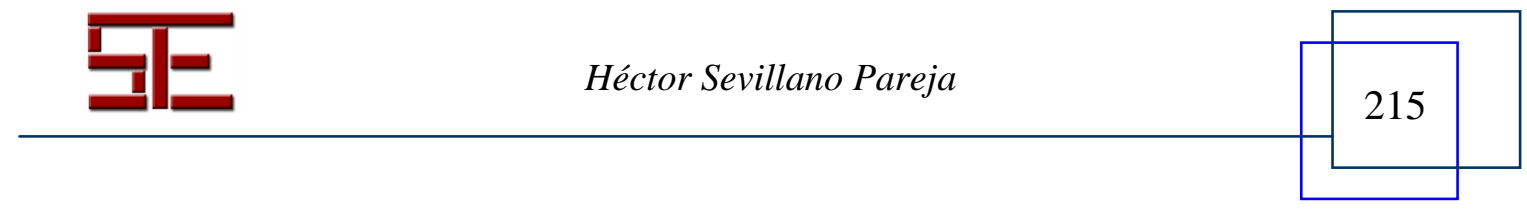




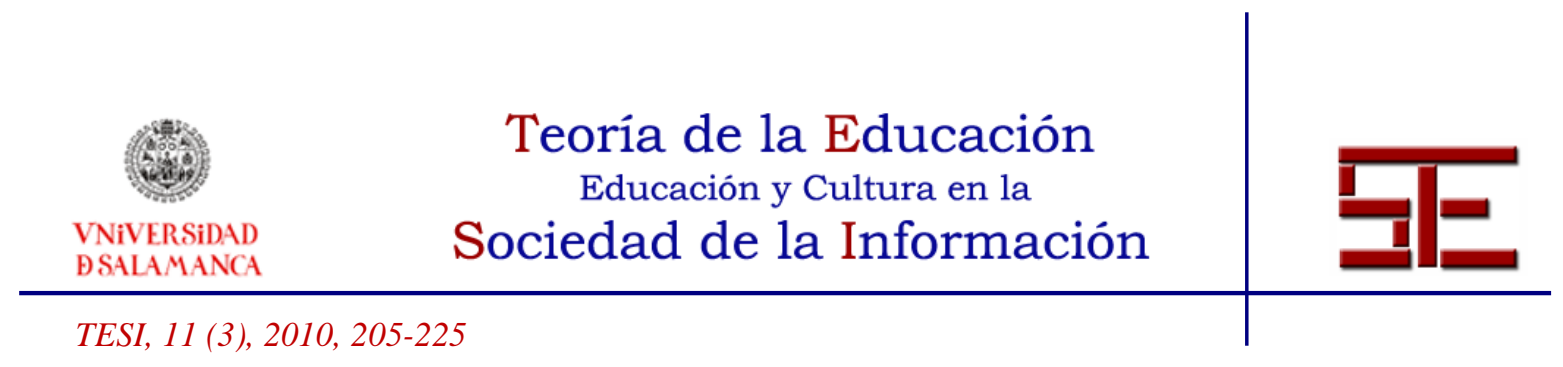

que son demasiado pequeñas y con un volumen de negocio tan bajo que no resultan interesantes para ninguna de las editoriales grandes.

La cuestión de los premios de las editoriales igualmente ha sido de nuestro interés. Actualmente ninguna de las editoriales tiene premio propio, Nosolorol no tiene ni ha tenido, sin embargo, las otras editoriales sí lo han intentado, aunque al final lo han acabado retirando por falta de participación o de calidad de lo presentado.

Sobre la experiencia que han adquirido en este sector editorial de los juegos de rol, los tres editores destacan la cercanía del público como lo más reseñable.

Consultados por la posibilidad de abrir nuevas sucursales o de modificar la ubicación de su actual sede, todos los editores rechazaron la posibilidad de abrir más delegaciones ${ }^{[18]}$ y señalaron que la ubicación de la sede, en principio, se escogió por la presencia de los colaboradores en esa ciudad.

A partir de su línea editorial intentamos concluir si habría en un futuro un cambio en el peso que ejercían las traducciones en el total del catálogo. Devir considera que lo que les demanda el público es mantener el peso de los autores anglosajones, Sombra conservará su elenco de obras españolas y Nosolorol seguirá defendiendo un mayor peso en su catálogo de libros españoles, aunque aumentará las traducciones. Mas ninguna se plantea traducir obras que no vengan del inglés. Visto lo cual, Nosolorol y Sombra apuestan por el rol de origen nacional y Devir por las traducciones, con la única excepción de El Capitán Alatriste.

Como actividades complementarias Nosolorol y Sombra tienen sendas revistas electrónicas (Nosolorol y Desde el sótano, respectivamente) y además la editorial de Sueiro tiene una tienda virtual. Devir, sin embargo, delega estas actividades, principalmente reservadas a juegos de tablero y cartas, a la distribuidora, quedándose ellos con las actividades de los juegos de rol.

${ }^{[18]}$ Haciendo un poco de historia de las editoriales, Sombra tiene sólo la oficina principal en Manises. Devir al ser filial de una empresa brasileña, cuenta en la Península con una oficina en Lisboa y Nosolorol tiene su sede en Madrid.

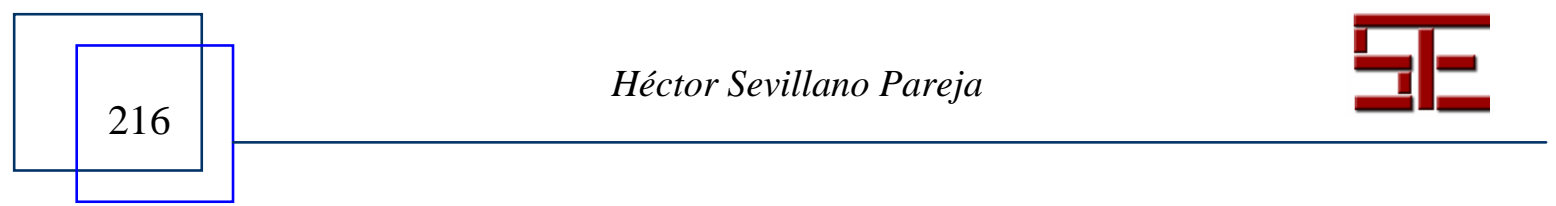




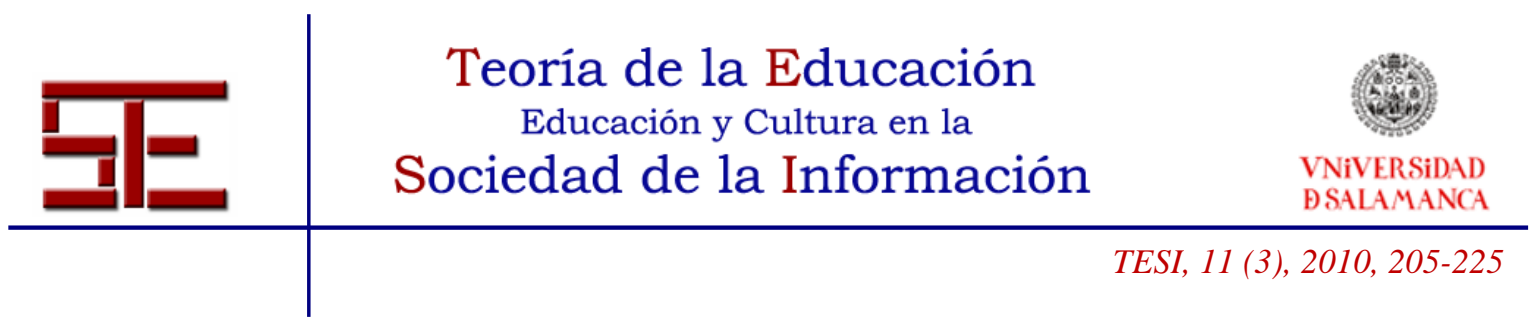

Respecto a los autores, todas las editoriales tienen un conjunto de autores fijos aunque reconocen que está abierto a nuevas incorporaciones. Hasta aquí llega el planteamiento común de estas empresas ante el modo de ver a los autores. A partir de aquí hay dos puntos de vista enfrentados, Devir edita a partir de lo que publican los autores (relativamente cierto pues los libros de $D \& D$ son mayoritariamente encargos de Wizards a determinados autores y que posteriormente publica esta editorial) y por tanto no suele encargar obras. Por el contrario Sombra encarga los libros a los autores. El problema que surge con los autores españoles es que todos suelen tener otra ocupación pues escribir rol es una afición en España y hasta el momento no un modo de vida. Eso sí, habitualmente son autores todoterreno.

Preguntados por la nacionalidad de los autores de sus respectivos catálogos, en Devir la mayoría son de origen norteamericano (por el peso específico que supone $D \& D$ ) y en las otras dos editoriales es casi exclusivamente español.

En el tema de las negociaciones con los autores, todas las empresas suelen tratar directamente con ellos. La excepción a esto estaría en Devir, ya que algunos autores poseen agente literario.

Metidos en las funciones del editor, los tres entrevistados reconocen que realizan de todo un poco en sus editoriales respectivas, leer, planificar los títulos, ir a las ferias, etc., aunque esto se agudiza en el caso de Sombra o Nosolorol que apenas cuentan con plantilla. Solamente Nosolorol cuenta con algo parecido a un consejo editorial, pero externo a la misma, compuesto por personas con una amplia experiencia y que sugieren, comentan, corrigen y ejercen de comité de lectura. Para la figura del comité de lectura, en el caso de Sombra se recurre a un grupo de personas ajeno a la editorial para que ojeen el material externo que les llega. Devir por el contrario sí cuenta con una serie de lectores fijos que supervisan determinadas obras que por volumen o falta de tiempo no puede supervisar él.

Continuando con la plantilla, la figura del traductor es diferente según la editorial, aunque por lo comentado hasta ahora podemos hacernos una idea ya de su situación. Devir prefiere contar habitualmente con traductores freelance, Nosolorol aunque no tiene traductores en plantilla, al final siempre cuenta con los mismos y Sombra directamente no tiene pues no traduce. Estas compañías carecen del resto de la plantilla común a cualquier gran editorial, excepto la figura del ilustrador, con la que cuentan las

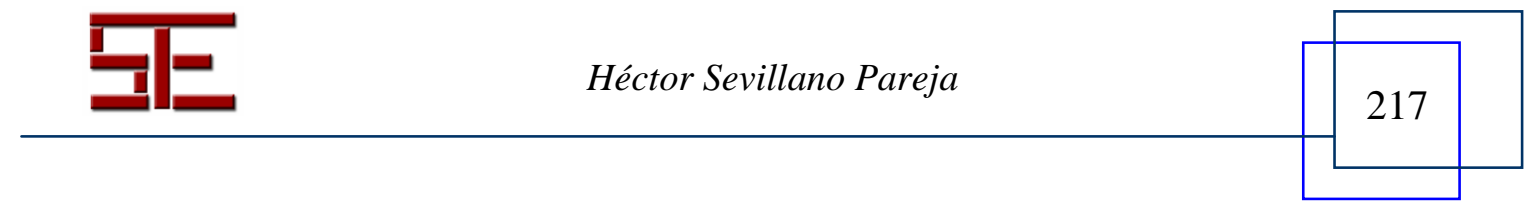




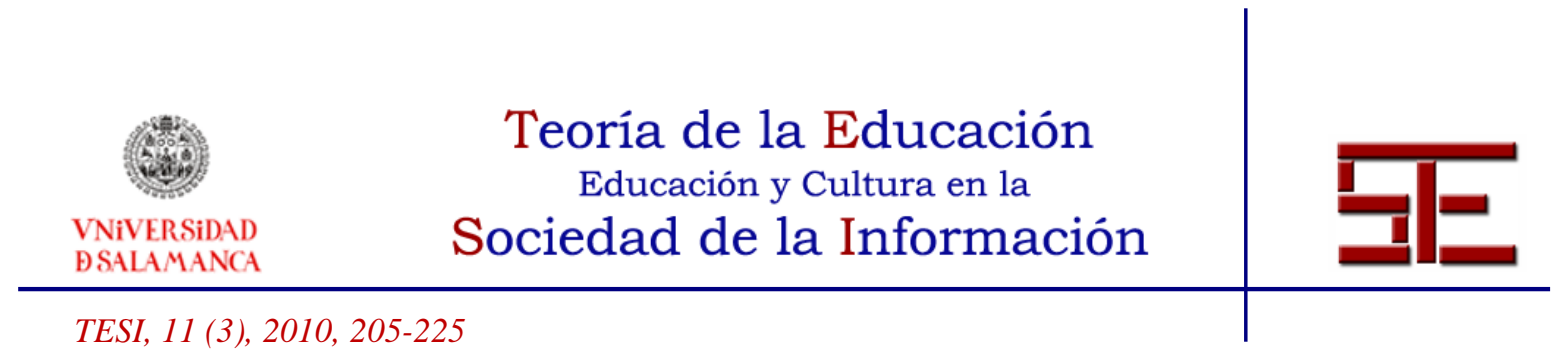

tres empresas, el resto (ya sea director artístico, fotógrafos, etc.) buscan a las personas idóneas para el trabajo cuando surge la necesidad. Solamente hay otra figura que también existe en la plantilla de Devir (no en el resto, recordemos que las plantillas de Sombra y Nosolorol están compuestas por dos personas), el documentalista.

Las obras a publicar se fijan con criterios de mercado, es decir, teniendo en cuenta la demanda imperante y la carga de trabajo que pueda salir adelante.

El fondo editorial lo componen en este tipo de empresas las líneas o colecciones de juego, salvo algunos casos de libros sueltos y editados siempre en papel. La salvedad al papel la tienen las revistas electrónicas de Sombra y Nosolorol. Preguntados por si ven posible colgar sus productos en Internet en formato PDF, como hacen algunas editoriales americanas que bajan así el precio de sus obras, todos los editores lo han considerado, pero ninguno lo ve posible para su editorial, por lo menos a corto plazo.

Sobre la línea editorial, ninguno de los encuestados pretende variar su orientación a la búsqueda de nuevas franjas de edad. Resulta curioso observar que Devir considera que está orientada hacia un público juvenil, las otras dos editoriales creen que se dirigen a un público adulto.

Otro aspecto interesante a contemplar en las editoriales es la distribución y la comercialización. Devir España se encarga del catálogo, de la compra de los derechos del libro y de la gestión en castellano, mientras que su sección en Portugal dirige la logística. En el caso de Nosolorol la distribución la gestiona una distribuidora externa y en el de Sombra lo hace la misma empresa. El método de venta es directo en el caso de esta última y en las otras dos combinan el método de distribución ajeno y directo. En Devir esto es así porque vende directamente a algunas tiendas y a través de la tienda on line e indirectamente a través de agentes o de los distribuidores regionales. Algo similar ocurre con Nosolorol, que vende directamente a partir de su tienda on line y de forma ajena a través de la distribuidora.

En relación a los canales de venta, Devir surte directamente a algunas tiendas y la distribuidora se encarga de las grandes superficies, es más, algunos de sus libros han estado en el catálogo del Círculo de Lectores. Juan Carlos Herreros y Manuel Sueiro, por el contrario, se conforman con la venta a través de librerías y por correspondencia. Solamente Juan Carlos Herreros ha logrado contactar con alguna biblioteca para surtirla de sus productos. Es decir, las editoriales no emplean a las bibliotecas como posible

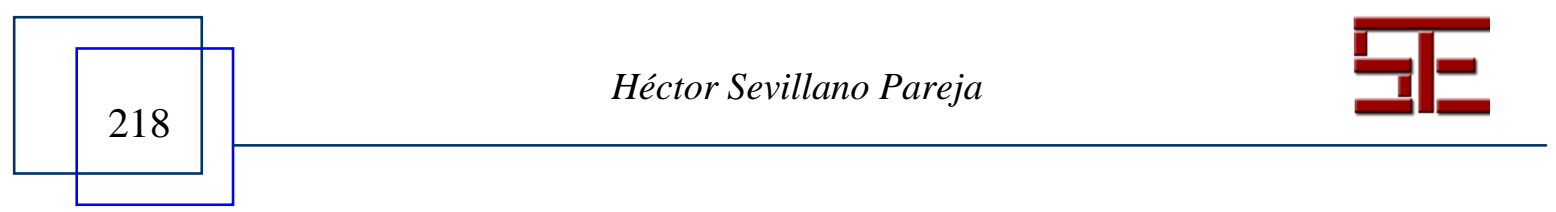




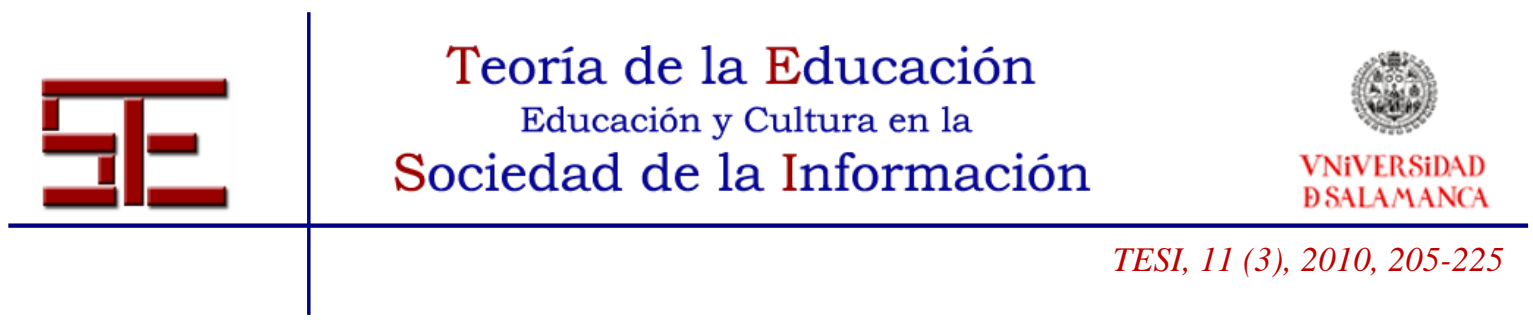

cantera para crear futuros aficionados al rol, puesto que solamente Ediciones Sombra surte de productos directamente a la biblioteca municipal donde tiene su sede social.

Metidos en la comercialización, se les preguntó a los editores sobre si realizaban descuentos en los precios dependiendo del canal de distribución. Sombra no los hace, Nosolorol sí (conforme a la legislación vigente) y Devir lo deja en manos del distribuidor, pero lo que influye es el volumen del pedido.

Quisimos conocer las posibilidades de exportación que tienen los productos de las editoriales de juegos de rol. Las dos más pequeñas (Sombra y Nosolorol) no exportan, salvo casos puntuales bajo demanda de jugadores españoles en el extranjero. El caso de Devir es bien distinto, ya que tiene abierta una sucursal en Estados Unidos para gestionar el mercado latinoamericano, además de la división de Devir para Brasil.

Los índices de devoluciones suelen ser motivo de quebraderos de cabeza para los editores. En estas editoriales esto no es así. Es cierto que se producen devoluciones, o así lo reconocen los editores, pero los porcentajes son mínimos en lo que a rol se refiere, pues rondan entre un $1 \%$ y algo menos de un $5 \%{ }^{[19]}$. Estas devoluciones varían dependiendo del canal utilizado, librerías y distribuidoras mayoritariamente, siendo raras las devoluciones en los casos de venta directa.

Otro apartado importante es el de la promoción. Devir posee para ello un servicio de prensa, si bien las otras editoriales tienen que confiar esa tarea en algún colaborador, para que anuncie las novedades y demás noticias en los medios especializados. Los medios en que ofertan los productos varían según cada editorial, aunque compartirían el uso de la publicidad a través de diferentes webs de rol, el boca a boca y la presencia física en las jornadas (esto último sobre todo las editoriales Sombra y Nosolorol). En lo concerniente a las notas de prensa, éstas las hacen los editores, salvo en Devir en la que lo hace la directora de marketing.

Para la promoción las editoriales usan diferentes tácticas consistentes en: la publicación de catálogos de productos para las tiendas, presencia en los foros de Internet de los

${ }^{[19]}$ Según Laura Requejo (Requejo, 2005, 31): “...La tasa general de devoluciones para 2003 fue de un $31,4 \% . . .$, muy alejada por lo tanto de las cifras que ofrecen las editoriales de rol.

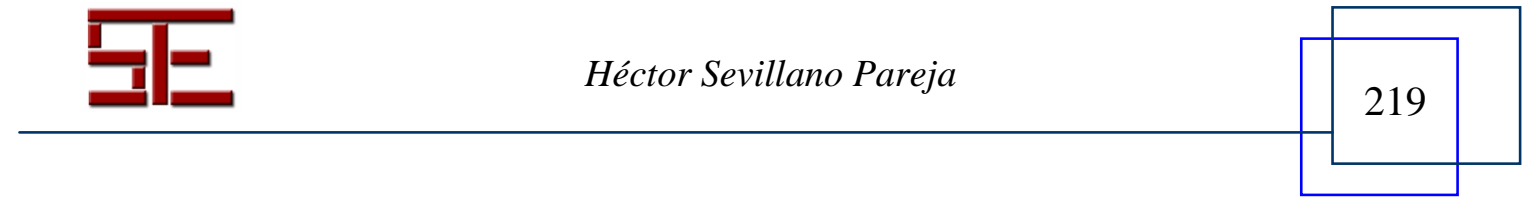




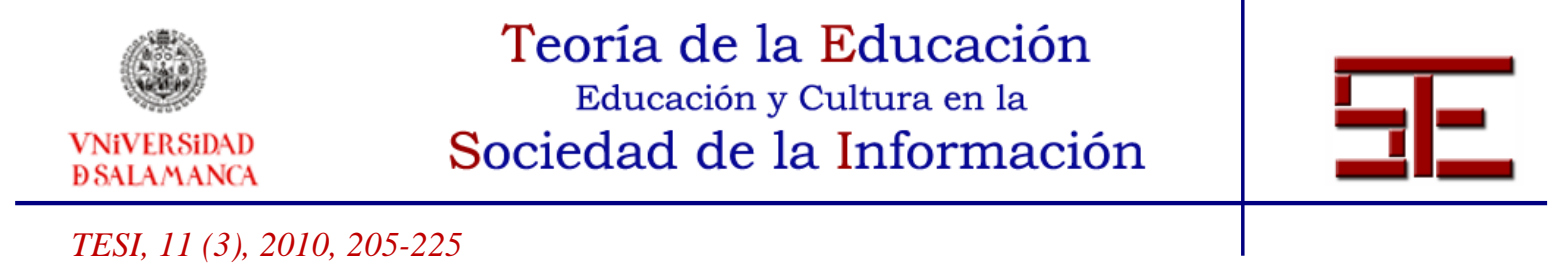

aficionados (de las cinco editoriales más potentes, en la actualidad cuatro de ellas mantienen foros de aficionados. Devir los tuvo en su momento pero los cerró) y asistencia a jornadas, en donde se hacen actividades relacionadas con los productos de cada editorial (Nosolorol además suele repartir merchandising en estas jornadas). Las jornadas son seleccionadas siguiendo criterios basados en el número de asistentes y económicos. Devir además posee agentes comerciales que presionan en los puntos de venta para que sus productos estén más visibles.

Por último se les preguntó sobre la cobertura geográfica que intentaban dar a la publicidad de la empresa. Todos los editores respondieron que querían una cobertura nacional.

\section{3.- BIBLIOGRAFÍA.}

Álvarez, P. (2006). Panorama 2005 edición ficción, La Factoría de Ideas. Delibros, 19 (194), 56.

Ávila, A. Ma . (2006). Los problemas de la industria del libro. Delibros, 19 (197), 20-26.

Barrena, P. (1996). Adolescentes: objetivo editorial. Delibros, 9 (94), 43-45.

Bernasocci López, A.; López de Abiadia, J. M.; Neuschäfer, H.J. (eds) (2001). Entre el ocio y el negocio: industria editorial y literatura en la España de los 90. Madrid: Verbum

Birkerts, S. (1999). Elegía a Gutenberg: el futuro de la lectura en la era electrónica. Madrid: Alianza.

Bourdieu, P. (1999). Une révolution conservatrice dans l'édition. Actes de la Recherche en Sciences Sociales, 126/127, 3.

Calzado, M.R. (2003). De cómo se descubre un libro. La promoción editorial. Delibros, 16 (167), 36-38.

Castillo, M. Á. (1999). El Mercado editorial. Delibros, 12 (118), 18-24.

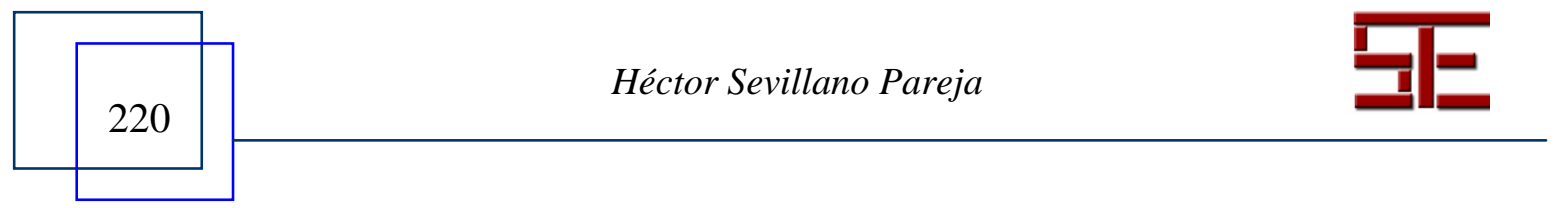




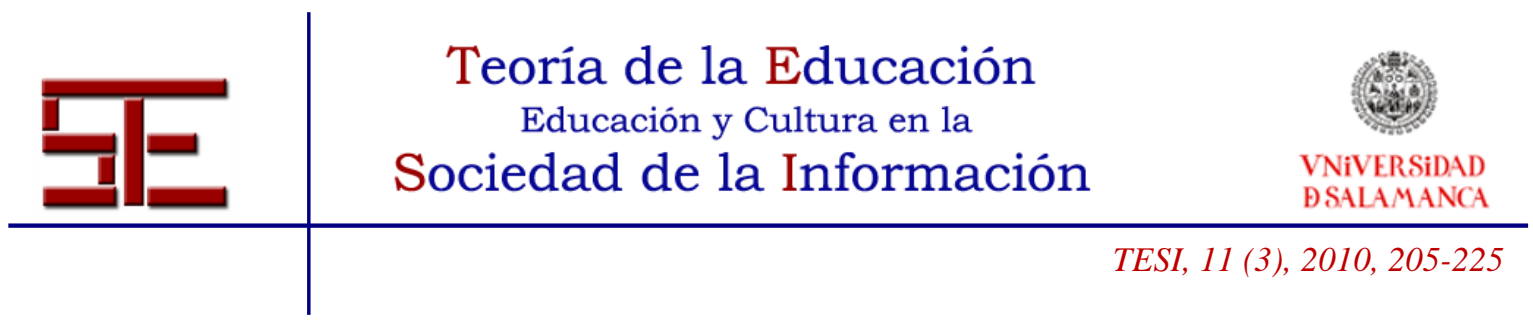

- 2006a): Dossier: Precio de los libros ¿fijo? Delibros, 19 (196), 18-22.

- (2006b): Leyes que regulan el mundo del libro. Delibros, 19 (195), 24-30.

Cavaliere, A. (2005): El libro impreso y el libro digital: estudio sobre los modos de producción editorial en el cambio de milenio. San Vicente del Raspeig. Alicante: Universidad de Alicante.

Cordón García, J.A. (et al.,) (1999). Las fuentes de información: estudios teóricoprácticos. Madrid: Síntesis.

- (1999): Manual de búsqueda documental y práctica bibliográfica. Madrid, Pirámide.

- (2002): La edición en España. Sintagma: revista de Historia del libro y de la lectura, Octubre, 113-136.

Cordon García, J. A.; López Lucas, J.; Vaquero Pulido, J. R. (2001). Manual de investigación bibliográfica y documental, teoría y práctica. Madrid: Pirámide.

DEUS101: Entrevista a los muchachos de Nosolorol. Dragonmania. Extraído el 1 de abril, 2009, de http://www.ociojoven.com/article/articleprint/976605/

Díaz Sacaluga, I. (2006). 99 espadas. Madrid: Nosolorol.

Días, O.; Poujade, J. C. (1994). La irresistible ascensión. Dosdediez, 5, 53-58.

Epstein, J. (2002). La industria del libro. Barcelona: Anagrama.

EQUIPO NOSOLOROL (2006, marzo 13). Entrevista a Manu y Ángel (Coautores sLAng). Nosolorol revista on line. Extraído el 1 de abril, 2009, de http://www.nosolorol.com/revista/index.php?nrev=34\&nsec=11 >

- (2006, mayo 17). Entrevista a Juan Carlos Herreros (Autor de Rol Negro). Nosolorol revista on line. Extraído el 1 de abril, 009, de

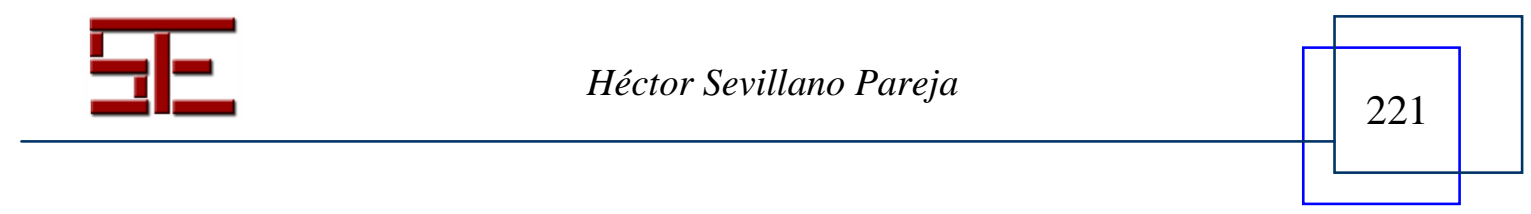




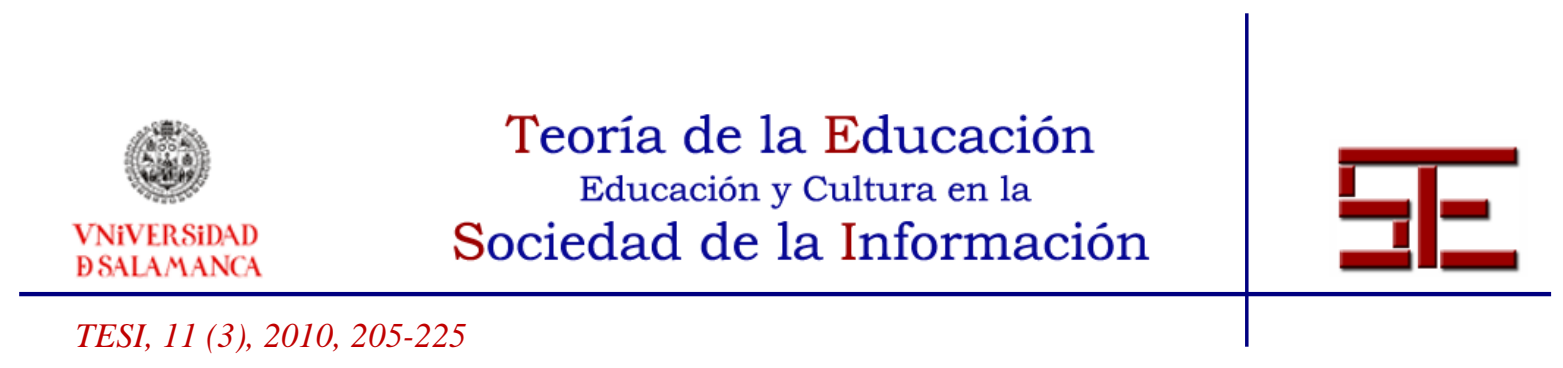

http://www.nosolorol.com/revista/index.php?nrev=36\&nsec=13 > [Consulta: 1 de abril de 2009].

García Castro, E. (2000). El carro de la Farsa, entrevista a Xavi Garriga. Líder, 5, 30-35.

González Gutiérrez, P.; Mañas Carbonero, L.; Laza Cebrián, J. D. (2007). Roleage, Evolved Roleplaying Game. Madrid: Nosolorol.

Hirchs, R. (1990). Libros, editores y público en la Europa moderna. Valencia: Alfons el Magnànim.

Holmgren, J. \& Hiel, P. (2006). Usagi Yojimbo. Madrid: Nosolorol.

Martínez DE Sousa, J. (2005). Manual de edición y autoedición (2 $2^{\mathrm{a}}$ edición). Madrid: Pirámide.

NOREN (2007, febrero 8). Entrevista a Manuel J. Sueiro, de Nosolorol Ediciones. Comicvia. Extraído el 20 de febrero, 2008, de http://www.comicvia.net/blog/?p=1196 >.

NOREN (2007, noviembre 19). Entrevista a Ediciones Sombra. Comicvia. Extraído el 20 de febrero, 2008, de http://www.comicvia.net/blog/?p=2232 y http://www.comicvia.net/blog/?p=2233 >. [Consulta: 20 de febrero de 2008].

Orúe, E. (2006). ¿Cómo se "caza" al lector? La importancia del marketing. Delibros, 19 (197), 38-40.

Peces, T. M. (2006). El futuro de la edición. Delibros, 19 (197), 46.

Requejo, L. (2005). Devoluciones: un problema con solución. Delibros, 18 (186), 31.

Revista de Libros (2006). La estrategia de precio de las editoriales. Delibros, 19 (196), 24-25.

Revista Líder (1995). Entrevista a Francesc Matas, 10 años de Joc Internacional. Líder, $45,14-15$.

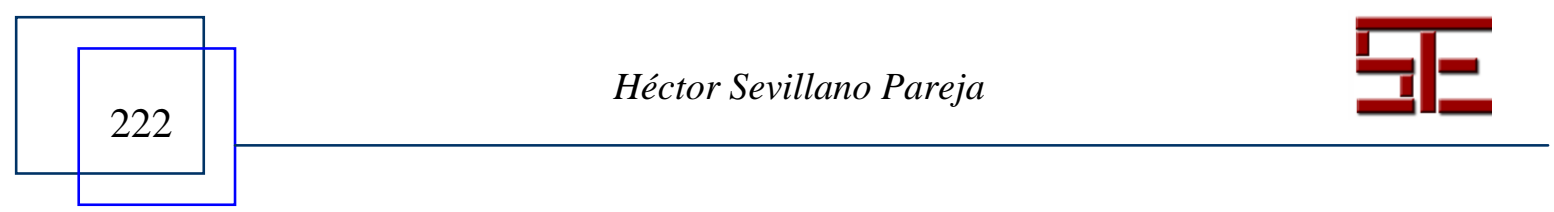




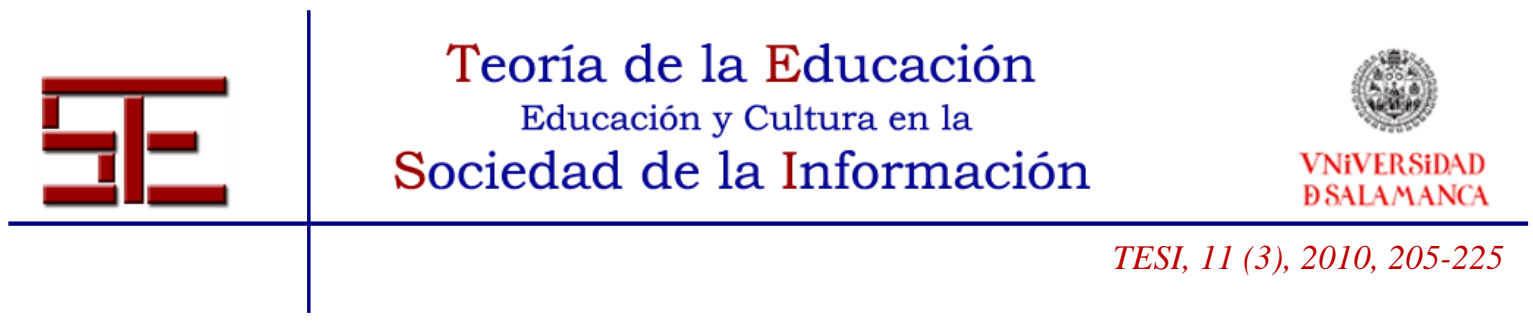

Sánchez, I.; Poujade, J. C. (1995). GENCON 94, el principio de algo grande. Dosdediez, 7, 18-23.

Sánchez Tarragó, N.; Díaz Álvarez, Y. Y. (2005). El sector editorial contemporáneo y las competencias profesionales. ACIMED, vol. 13, n 5, Ciudad de La Habana. Extraído el 1 de abril, 2009, de http://scielo.sld.cu/pdf/aci/v13n5/aci08505.pdf >

Schiffrin, A. (2000). La edición sin editores. Barcelona: Destino.

Tizón, R. (2007). Creer lo increíble, verdades y mentiras sobre los juegos de rol. Madrid: Nosolorol.

Vasel, T. 82005, junio 9). Real men play board games, Interviews by an Optimist 44 Xavier Garriga. The Dice Tower. Extraído el 1 de abril, 2009, de http://www.thedicetower.com/interviews/int044.htm >.

Velasco Suarez, A. (2000). Mercado de minorías: vías de investigación del circuito de consumo del libro de editoriales independientes. Coloquio de la Asociación Internacional de Bibliología, (vol.15, p.8). Extraído el 15 de noviembre, 2006, de http://www.fundacionyuste.org/acciones/aeb/XV\%20AIB2000/VELASCO.PDF

Para citar el presente artículo puede utilizar la siguiente referencia:

Sevillano Pareja, H. (2010). El perfil del editor de juegos de rol, en Orejudo González, J.P. (Coord.) Perspectiva educativa y cultural de "juego de rol". Revista Teoría de la Educación: Educación y Cultura en la Sociedad de la Información. Vol. 11, n ${ }^{\circ} 3$. Universidad de Salamanca, pp. 205-225 [Fecha de consulta: dd/mm/aaa].

http://campus.usal.es/ revistas_trabajo/index.php/revistatesi/article/view/7459/7476

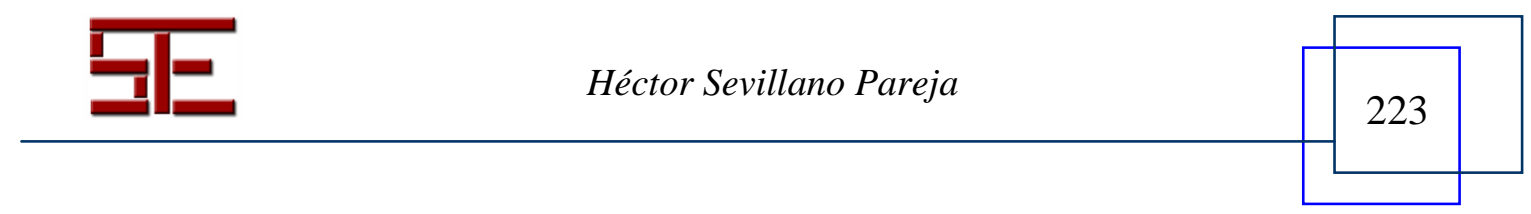




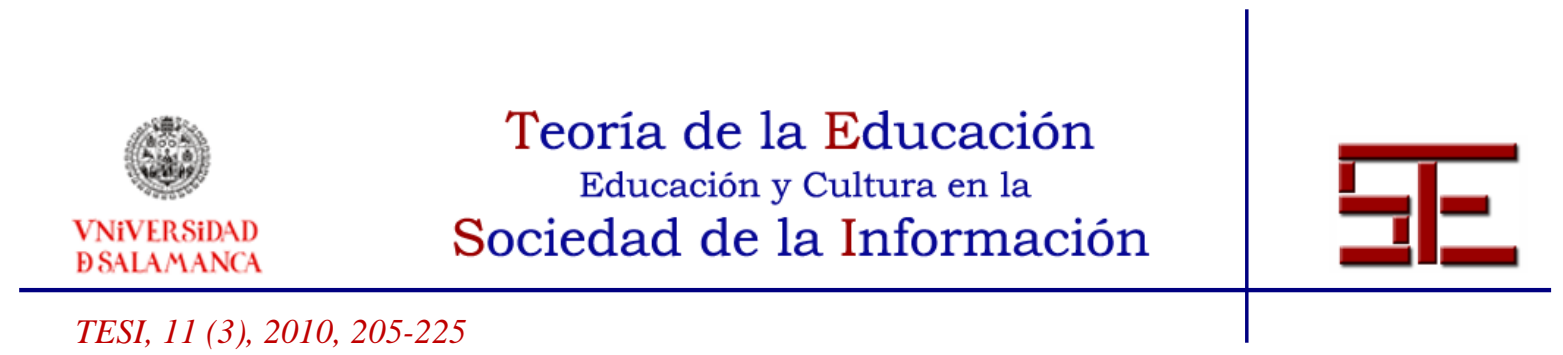

\section{FIGURAS}

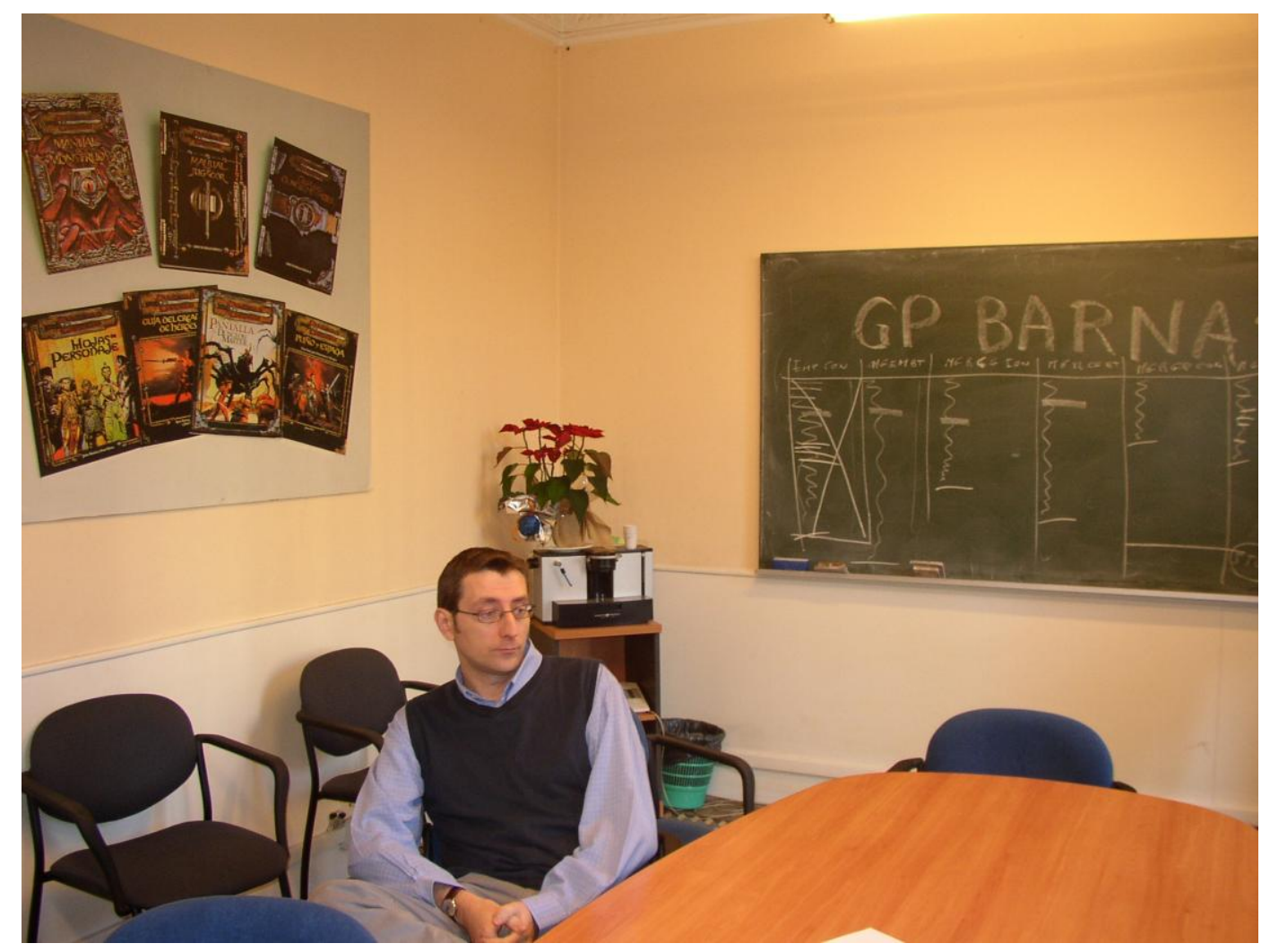

Fig. 1. Xavi Garriga en la sala de reuniones de Devir Iberia.

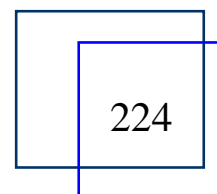



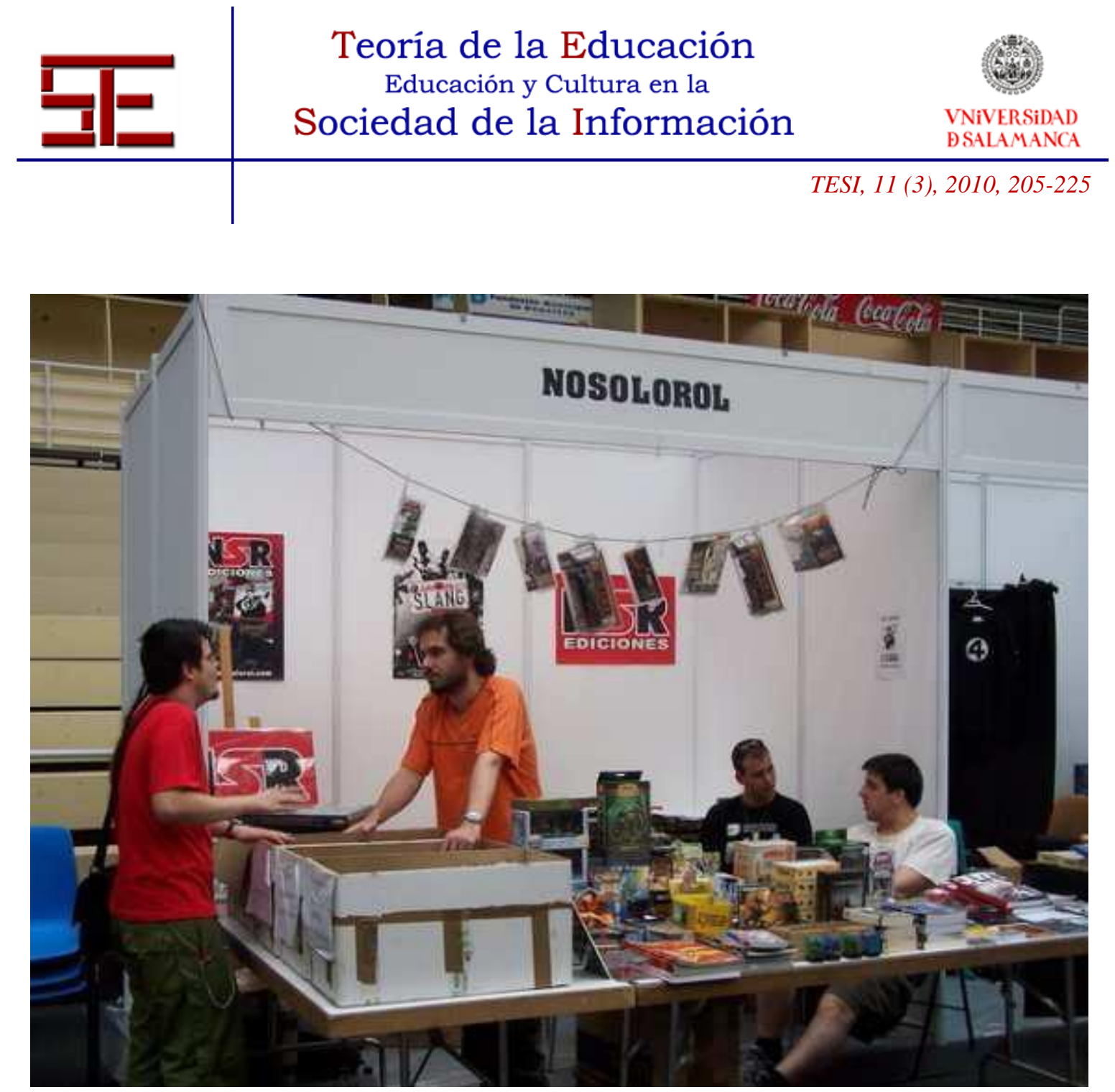

Fig. 2. Manuel José Sueiro y Abad (con camiseta naranja) atendiendo a un cliente en el stand de la editorial Nosolorol durante las PUCLN de 2006.

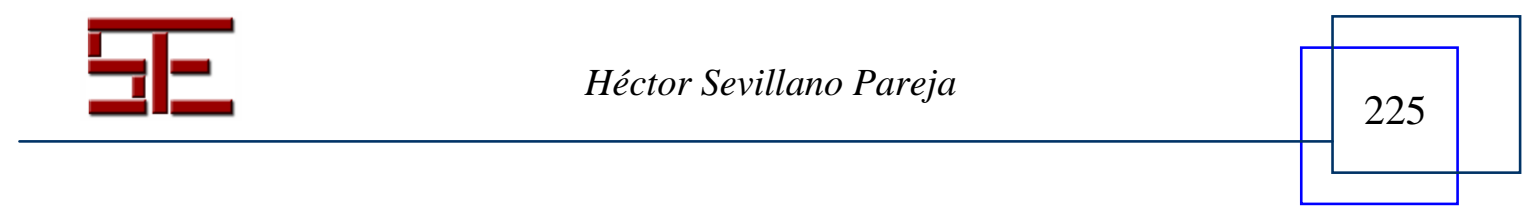

